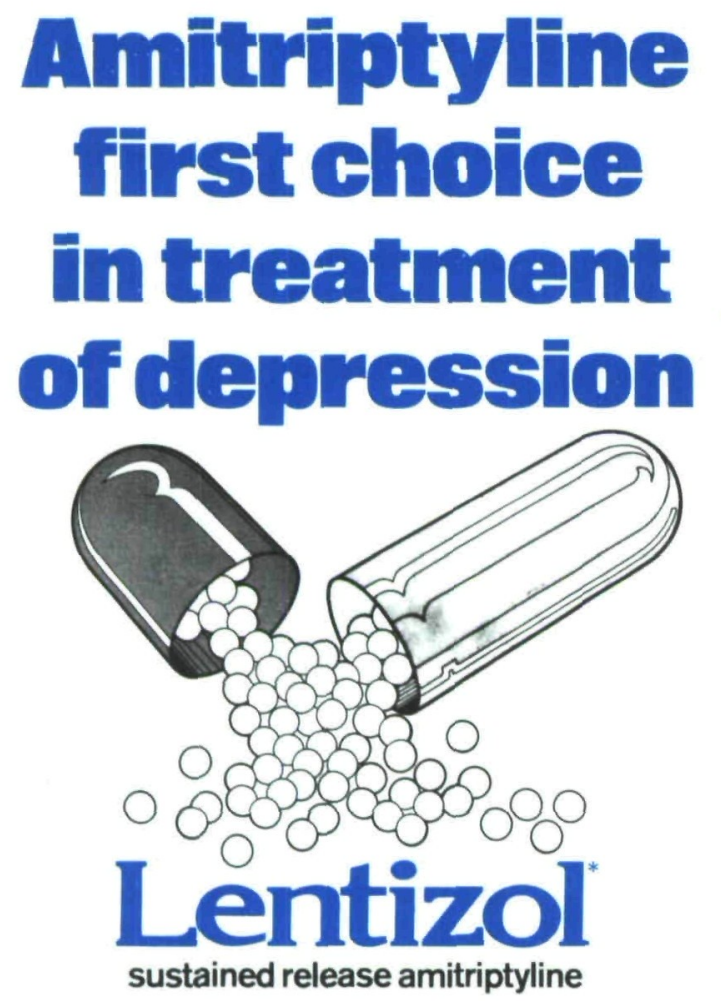

the obvious choice of amitriptyline'

- for your new patients

- for maintenance treatment of responders to amitriptyline

- Lentizol aids patient compliance by avoiding the need for multiple daily doses

1. Barton, JL. and Snaith, R.P Curr med Res.Opin., 1, 3, 133, 1972.

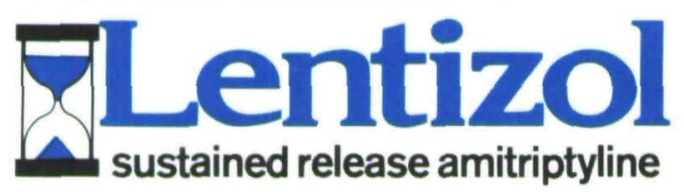

Further information is available on request William R. Warner \& Co. Ltd.

Usk Road, Pontypool, Gwent NP4 OYH

*Trade mark

6612-UK-DEC 78

\section{The Concepts of Illness, Disease and Morbus}

\section{F. KRÄUPL TAYLOR}

Dr Taylor's book analyses the disease concept as it developed in medical history and seeks to clarify it with the help of concepts largely derived from logical class theories. A solution is proposed to the problem of how to distinguish between the class of 'patients' and the class of 'healthy persons' which corresponds to the actual diagnostic practices of doctors.

The earliest theories of disease postulated concrete entities which exist independently of the body. The seventeenth-century view was that diagnostically important clinical manifestations were attributes of the disease entity and not of the patient. This view was challenged in the nineteenth century by Virchow for whom a disease entity was a pathologically altered part of the body. The notion of disease entity lost its original ontological connotations and instead its important feature became the possession of a unitary and self-contained character. Dr Taylor describes the modern theories as essentially 'reactive' in character, that is the symptoms of a disease are the bodily reactions to the 'noxae'. After setting the subject into its historical context, Dr Taylor goes on to discuss in detail the notion of the classification of diseases, making extensive use of modern views on the logic of classes. The book will be read by physicians, psychiatrists, historians of medicine and philosophers of science.

$£ 6.50$ net 
anti-depressant anti-anxiety anti-phobic/anti-obsessional Clomipramine
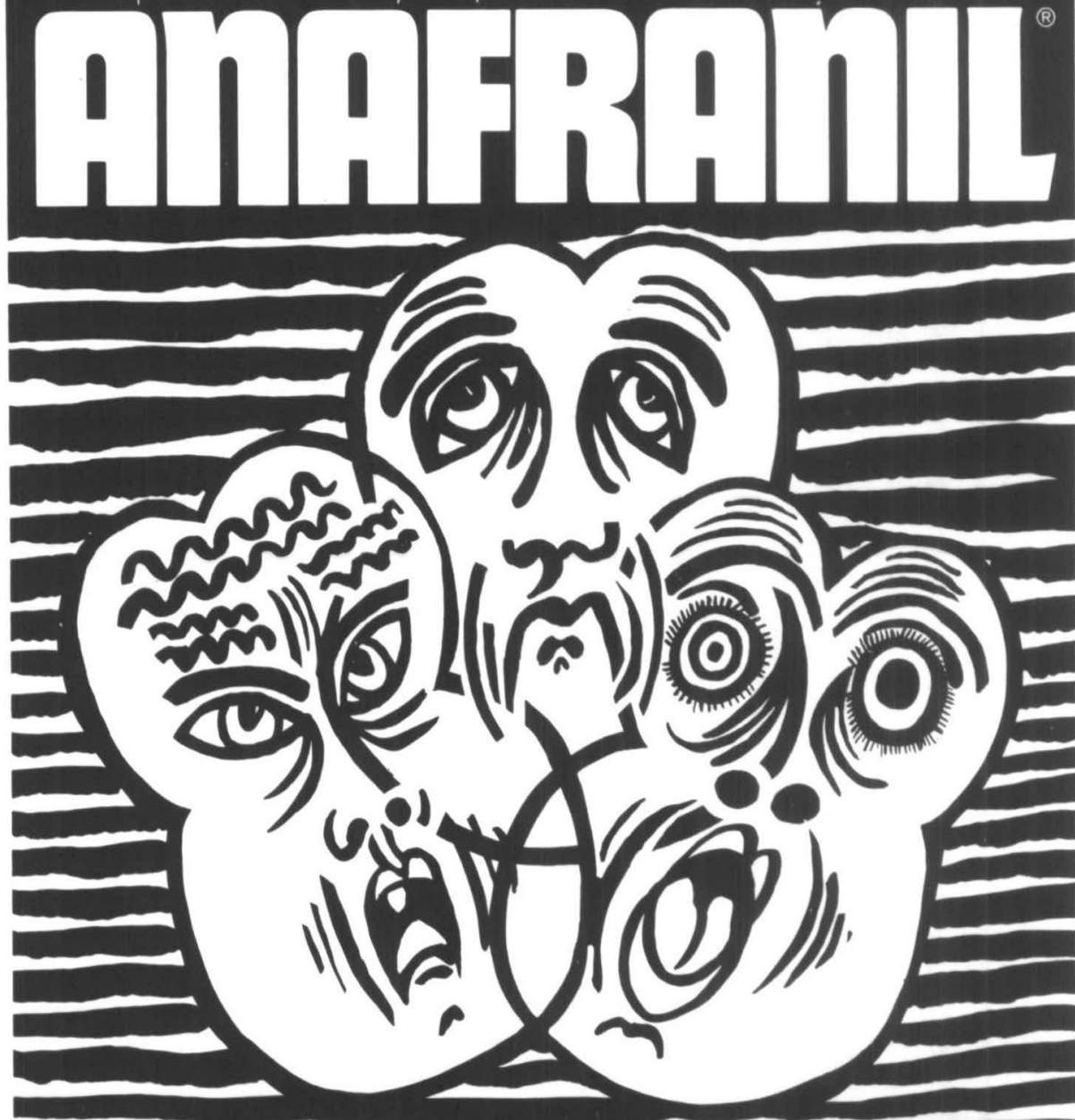

Since depression is frequently associated with anxiety and irrational fear Anafranil provides comprehensive therapeutic cover for the depressed patient in general practice

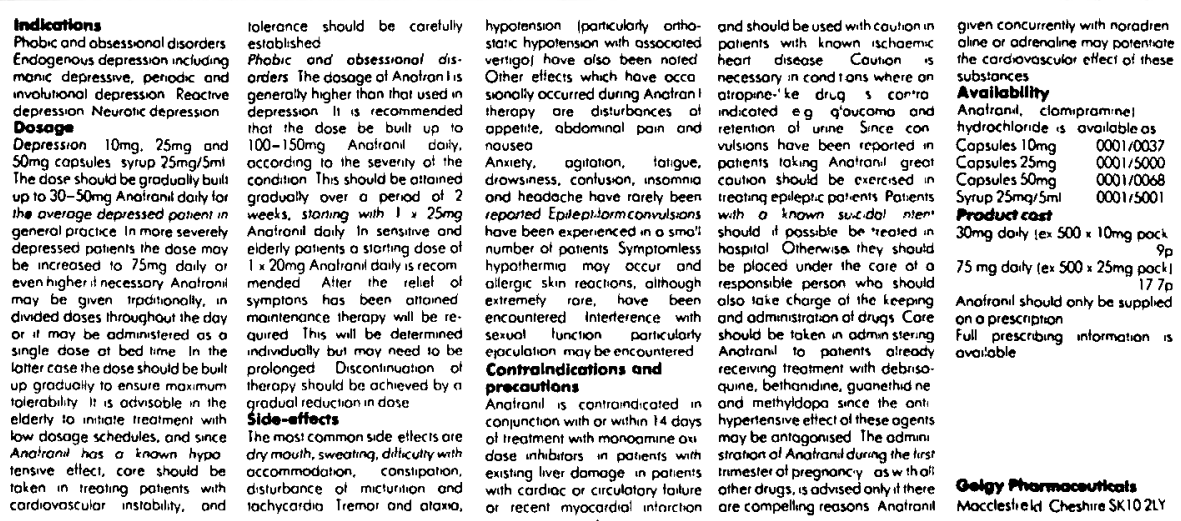

(ii) 


\section{Two \\ Essential Journals}

Send for a free examination copy!

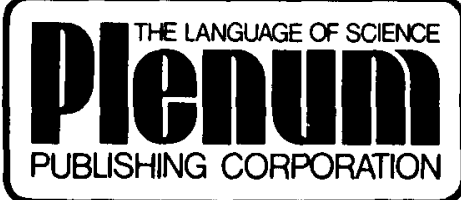

227 West 17th Street, N.Y., N.Y. 10011 In United Kingdom: Black Arrow House 2 Chandos Road, London NW10 6NR, England

\section{Journal of Behavioral} Medicine editor: W. Doyle Gentry, Ph.D. Duke University Medical Center

This broadly conceived interdisciplinary publication furthers our understanding of physical health and illness through the knowledge and techniques of behavioral science. Application of this knowledge to prevention, treatment, and rehabilitation is also a major function of the Journal, which includes papers from all disciplines engaged in behavioral medicine research.

Subscription: Volume 2,1979 (4 issues) $\$ 18.00$ (\$22.00 outside the U.S.) Institutional rate $\$ 36.00$ (\$42.00 outside the U.S.)

\section{Behavior Genetics} An International Journal Devoted to Research in the Inheritance of Behavior in Animals and Man executive editor: Jan H. Bruell University of Texas

Published in cooperation with the Behavior Genetics Association, this journal deals with the inheritance and evolution of behavioral characters in man and other species. Papers focus on the application of the various perspectives of genetics to the study of behavioral characters and with the influence of behavioral differences on the genetic structure of populations. In addition to papers reporting original studies, this journal publishes critical reviews and theoretical papers rele.vant to behavior genetics.

Subscription: Volume 9,1979 (6 issues) $\$ 79.00$ ( $\$ 90.00$ outside the U.S.) 


\section{NOTES FOR CONTRIBUTORS}

PA PER S Papers for publication should be addressed to the Editor, Professor Michael Shepherd, Institute of Psychiatry, De Crespigny Park, Denmark Hill, London SE5 8AF. Contributors should send at least three copies of the text, tables, and figures. Copies other than the first may be xeroxed. The S.I. system should be adopted for text and figures. A short synopsis of about 50 words should be provided at the beginning of each article. Foreign quotations and phrases should be followed by a translation. Submission of a paper will be held to imply that it contains original work that has not been previously published and that it is not being submitted for publication elsewhere.

In addition to longer articles, the Editor is prepared to accept preliminary communications of between 1500 and 2000 words.

Manuscripts must be typewritten on one side of the paper in double-spacing with wide margins. The following information must be given on a single separate sheet: (1) title and short title for running head (not more than 100 characters); (2) authors' names, and (3) department in which work was done. Footnotes on the same sheet should list: (i) the authors' present addresses if different from departments in which work was done; (ii) name and address of the author to whom correspondence should be addressed; (iii) receipt of grants. Authors who would like a reprint address to be printed should include this on their manuscript.

REFERENCES (1) In the text these should follow the Harvard system - that is, name followed by date: Brown (1970). If there are more than two authors the first author's name followed by et al. should be used, even the first time that the reference appears. (2) The list of references should be typed in alphabetical order on a separate sheet and should appear as follows: Brown, J., Williams, E. \& Wright, H. (1970). Treatment of heroin addiction. Psychological Medicine 1, 134-136. Journal titles should be given in full.

Books should be cited as follows: Brown, J. (1970). Psychiatric Research. Smith: Glasgow.

ILLUSTRATIONS Only essential figures and tables should be included. Photographs Unmounted photographs on glossy paper should be provided. Magnification scales, if necessary, should be lettered on these. Where possible, prints should be trimmed to column width (i.e. $70 \mathrm{~mm}$ ). Diagrams These will usually be reduced to $70 \mathrm{~mm}$ wide. Lettering should be in either Letraset or stencil, and care should be taken that lettering and symbols are of comparable size. Illustrations should not be inserted in the text, they should be marked on the back with figure numbers, title of paper, and name of author. All photographs, graphs, and diagrams should be referred to as figures and should be numbered consecutively in the text in Arabic numerals. The legends for illustrations should be typed on a separate sheet. Tables Tables should be numbered consecutively in the text in Arabic numerals and each typed on a separate sheet.

PROOFS AND OFFPRINTS Page proofs will be sent to the senior author. Corrections other than printer's errors may be charged to the author. Fifty offprints of each paper are supplied free; additional offprints are available according to a scale of charges if they are ordered when the proof is returned. 


\section{Psychological Medicine}

Volume 9 Number 3 August 1979

\section{CONTENTS}

EDITORIALS

The scientific status of electro-convulsive therapy

page 401

The epistemology of normality

409

Residential care of the elderly in Britain today

SCULL, A. T.

Moral treatment reconsidered: some sociological comments on an episode in the history of British psychiatry

RUSSELL, G. F. M.

Bulimia nervosa: an ominous variant of anorexia nervosa

SWIGAR, M. E., KOLAKOWSKA, T. AND QUINLAN, D. M.

Plasma cortisol levels in depression and other psychiatric disorders: a study of newly admitted psychiatric patients

CURzon, G., KANTAMANENI, B. D., LADER, M. H. AND GREENWOOD, M. H. Tryptophan disposition in psychiatric patients before and after stress

WOOD, R. L. AND COOK, M.

Attentional deficit in the siblings of schizophrenics

KREITMAN, N. AND SCHREIBER, M.

Parasuicide in young Edinburgh women, 1968-75

GOODHEAD, D. G., HUSSAIN, M. F. AND SEAGER, C. P.

Influence of experience and nationality on assessment and outcome of parasuicide

TURNER, R. J. AND MORGAN, H. G.

Patterns of health care in non-fatal deliberate self-harm

NEWSON-SMITH, J. G. B. AND HIRSCH, S. R.

Psychiatric symptoms in self-poisoning patients

URWIN, P. AND GIBBONS, J. L.

Psychiatric diagnosis in self-poisoning patients

FARMER, C. J., SNOWDEN, S. A. AND PARSONS, V.

The prevalence of psychiatric illness among patients on home haemodialysis

FARMER, C. J., BEWICK, M., PARSONS, V. AND SNOWDEN, S. A.

Survival on home haemodialysis: its relationship with physical symptomatology, psychosocial background and psychiatric morbidity

TENNANT, C., SMITH, A., BEBBINGTON, P. AND HURRY, J.

The contextual threat of life events: the concept and its reliability

WATT, D. C. AND SZULECKA, T. K.

The effect of sex, marriage and age at first admission on the hospitalization of schizophrenics during 2 years following discharge

TANTAM, D. AND BURNS, B. J.

An international comparison of two systems of community health care

WEEKE, A., KASTRUP, M. AND DUPONT, A.

Long-stay patients in Danish psychiatric hospitals

FRYERS, T.

Accumulating long-stay in-patients in Salford: monitoring further progress

SHEPHERD, G. AND RICHARDSON, A.

Organization and interaction in psychiatric day centres

BRIEF COMMUNICATION

Interactions in contingency tables: a brief discussion of alternative definitions

B. S. EVERITT AND A. M. R. SMITH

PRELIMINARY COMMUNICATION

The extent of mental and physical ill-health of clients referred to social workers in

a local authority department and a general attachment scheme R. H. CORNEY

BOOK REVIEWS 